\title{
Propagation of Measurement-While-Drilling Mud Pulse during High Temperature Deep Well Drilling Operations
}

\author{
Hongtao Li, ${ }^{1}$ Yingfeng Meng, ${ }^{1}$ Gao Li, ${ }^{1}$ Na Wei, ${ }^{1}$ Jiajie Liu, ${ }^{1}$ Xiao Ma, ${ }^{1}$ Mubai Duan, \\ Siman Gu, ${ }^{1}$ Kuanliang $\mathrm{Zhu}^{,}{ }^{2}$ and Xiaofeng $\mathrm{Xu}^{2}$ \\ ${ }^{1}$ State Key Laboratory of Oil and Gas Reservoir Geology and Exploration, School of Petroleum Engineering, \\ Southwest Petroleum University, Chengdu 610500, China \\ ${ }^{2}$ Drilling and Production Technology Institute, PetroChina Jidong Oilfield Company, Tangshan 063000, China \\ Correspondence should be addressed to Yingfeng Meng; cwctmyf@vip.sina.com and Gao Li; lgmichael@263.net
}

Received 19 January 2013; Accepted 8 April 2013

Academic Editor: Fazal M. Mahomed

Copyright (C) 2013 Hongtao Li et al. This is an open access article distributed under the Creative Commons Attribution License, which permits unrestricted use, distribution, and reproduction in any medium, provided the original work is properly cited.

\begin{abstract}
Signal attenuates while Measurement-While-Drilling (MWD) mud pulse is transmited in drill string during high temperature deep well drilling. In this work, an analytical model for the propagation of mud pulse was presented. The model consists of continuity, momentum, and state equations with analytical solutions based on the linear perturbation analysis. The model can predict the wave speed and attenuation coefficient of mud pulse. The calculated results were compared with the experimental data showing a good agreement. Effects of the angular frequency, static velocity, mud viscosity, and mud density behavior on speed and attenuation coefficients were included in this paper. Simulated results indicate that the effects of angular frequency, static velocity, and mud viscosity are important, and lower frequency, viscosity, and static velocity benefit the transmission of mud pulse. Influenced by density behavior, the speed and attenuation coefficients in drill string are seen to have different values with respect to well depth. For different circulation times, the profiles of speed and attenuation coefficients behave distinctly different especially in lower section. In general, the effects of variables above on speed are seen to be small in comparison.
\end{abstract}

\section{Introduction}

The oil industry trend to deep formation exploration has increased technological challenges to drill. An important problem in deep drilling is the propagation of MeasurementWhile-Drilling (MWD) mud pulse, transmitting real-time various data from sensors (accelerometers, magnetometers, Gamma Ray sensor, etc.) located downhole near the drill bit [1]. MWD systems can provide important information $[2,3]$, such as inclination and azimuth of the wellbore, tool face, formation properties, rotating speed of the drill string, torque and weight on bit, and mud flow volume, which is critical and indispensable to deep well drilling. Mud pulse telemetry is the most common method of data transmission used by MWD. In deep formation environments, where the temperature and pressure are prevalently high, dynamic of mud and its density behavior in drill string are very different from those in normal conditions [4]. This aggravates the attenuation of mud pulse, eventually reduces the signal strength at the surface, and makes detection of the signal more difficult. This paper considered the propagation behavior of MWD mud pulse in drill string during high temperature deep drilling operations.

Understanding the propagation and attenuation characteristics of mud pulse in drill string still needs strong theories to be formulated together with reliable smart experiments. The prime factor which opposes any pressure wave propagation is the irreversibility of the process associated with friction [5]. Therefore, wall shear stresses and molecular interactions between adjacent flow layers have to be accurately quantified. In addition, the mud density behavior during high temperature and high pressure drilling operations has to be considered, which directly affects the propagation of mud pulse. A simple theoretical model simulating the propagation of mud pulse was first proposed by Chen and Aumann [6], with a numerical solution. In the proposed model, only wall shear stresses were considered. Liu et al. [7] proposed 
a mathematical model to simulate the dynamic transmission behavior of mud pulse. Essentially, what was proposed is still a single phase model, despite the fact that a multiphase formula in the paper is used to calculate mud solids and free gas content change. Besides, the authors merely considered the effects of wall shear stresses and inclination. A real multiphase flow model simulating the propagation of mud pulse in aerated drilling was derived by $\mathrm{Li}$ et al. [8]. It is thought that the effects of the momentum and energy exchange at phase interface, gravity of each phase, and wall shear stresses on mud pulse propagation were taken into account. However, the model cannot be used in high temperature deep well drilling, where primary circulating fluids are single phase, and the density behavior of mud and friction between adjacent flow layers cannot be neglected. Up to date, no complete mathematical model of mud pulse propagation in drill string during high temperature deep drilling operations has been derived.

The mud pulse discussed in this paper can be interpreted as pressure wave in the fluid down the drill string, a kind of typical hard walled rigid pipe, which propagates with the speed of sound through fluid flow [9]; the speed of sound depends on the type and temperature of the fluids for a given pipe [10]. In transient analysis of the pipe flow, the transmitting of pressure wave can be looked on as a forced oscillatory motion process [11]. There is a large body of literature on the propagation of pressure wave in rigid pipe with hard walls. Binder [12] studied fluid vibrations in a tube with friction. He gave an expression for total excess pressure at any point in a straight rigid tube of constant cross-sectional area filled with a compressible fluid. Lighthill [13] discussed the dissipation of acoustic energy and the mechanisms modifying the linear theory of sound. Brown [14] studied the dispersive mechanism in transmission systems and gave a prediction of dispersion in fluid lines with laminar flow. Iberall [15] and Nichols [16] analyzed, respectively, the behavior of unsteady laminar flow in a long rigid pipe used the method of characteristics. Based on the Iberall model of fluid transients, Jayasinghe et al. [17] derived a frequency-dependent friction coefficient for laminar pipe flow of compressible fluids. Zielke [18] has indicated that the method of characteristics can handle frequency-dependent absorption. He related the wall viscosity to the weighted past velocity change and the instant mean flow velocity. Suzuki et al. [19] have proposed an improved method of characteristics without losing the accuracy, but it seems to be complicated. Brunelli [20] reported recently a computational method to calculate two-dimensional velocity profiles under the compressible fluid condition. The frequency-dependent absorption was taken into account in his method. A nonlinear wave equation was reported by Kuznetsov [21], similar to Blackstock [22] formulation. A higher order formulation of nonlinear wave equation was investigated by Chester [23]. Acoustic wave propagation in circular ducts with hard walls containing shear flow has been studied by a number of researchers (see, e.g., references [24-32]). In most cases the mean velocity profile of shear flow has been taken as that of fully developed laminar flow or as a uniform core flow with a thin boundary layer at the wall. Agarwal and Bull
[33] presented theoretical results for sound propagation in a hard walled pipe with a fully developed turbulent flow profile. Auslander [34] predicted the frequency response of fluid lines with turbulent flow. Experimental tests were conducted to inspect the contributions of unsteady friction on pressure wave [35]. Brunone et al. [36] matched the test results to a classical one-dimensional elastic water hammer model coupled with an unsteady friction model, known as Brunone's corrected unsteady friction model. Semiempirical analytical and experimental studies of the acoustic frequency response of circular tubes with mean turbulent flow have been made by Brown et al. [37]. They discussed the behavior of amplitude disturbances superimposed on a gross turbulent flow and proposed an equation for calculating the wave attenuation factor. Numerical solutions based on the method of characteristics were applicable to the modified wave attenuation, as shown by Wylie and Streeter [11]. Mitra and Rouleau [38] developed a numerical method for fluid transients in rigid pipes, based on implicit factorization. Stuckenbruck et al. [39] gave numerical results of an improved analysis of wave speed. Pressure wave transmission attenuation in a pipe flow was investigated both theoretically and experimentally by Wang et al. [5]. Sato and Kanki [40, 41] obtained the analytical solutions for the compression wave and steady state oscillating flow in a pipe with a circular cross-section. However, previous researches have not provided a simple and reliable analytical model for calculating the mud pulse speed and attenuation in a viscous fluid pipe flow, where the effect of density behavior in high temperature deep well environments on mud pulse transmission cannot be neglected.

The objective of the present work is to study the propagation and attenuation of mud pulse in high temperature deep well drilling. In this paper, besides, and the wall shear stresses, gravitational effects, the molecular interactions between adjacent flow layers were also deeply analyzed, in addition to the effect of mud density behavior on the propagation and attenuation of mud pulse. By performing linear perturbation analysis to solve nonlinear differential governing equations, newly analytical formulas of speed and attenuation factor have been developed.

\section{Mathematical Model and Solutions}

A one-dimensional analytical model for mud pulse propagation and attenuation in drill string during high temperature deep well drilling is developed, and by performing a linear perturbation analysis, we derived the mud pulse speed and attenuation factor formulas.

Some basic assumptions for the formulation of the model are as follows: the mud liquid constitutes a continuum. Oscillatory motion process aroused by mud pulse transmission is of momentum conservation. Besides, the motion process is isentropic.

2.1. Governing Equations. In drilling, we consider the mud pulse travelling along drill string through single phase mud fluid, which is shown in Figure 1. Mud pulse transmits in $-x$ direction, reversing the mud flow, and the pipe wall is 


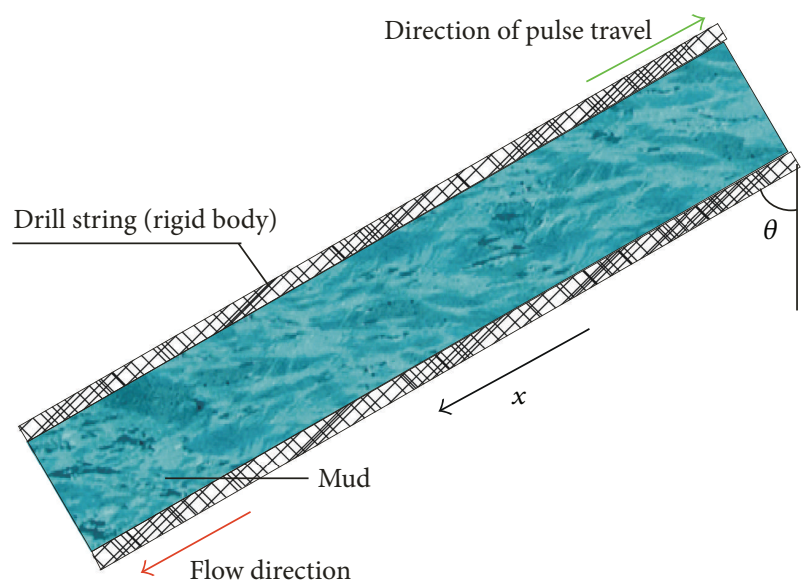

FIgURE 1: Mud pulse propagation in drilling.

a rigid body. It is assumed to be laminar flow. In addition, it is assumed that $p$ and $v$ are independent of the circumferential angle around the pipe axis. The mud flow behavior in drill string can be described using the one-dimensional nonlinear differential equation of continuity and motion as follows:

$$
\begin{gathered}
\frac{\partial \rho}{\partial t}+\rho \frac{\partial v}{\partial x}+v \frac{\partial \rho}{\partial x}=0 \\
\rho \frac{\partial v}{\partial t}+\rho v \frac{\partial v}{\partial x}=-\frac{\partial p}{\partial x}-\rho g \sin \theta-\frac{\lambda}{2 d} v^{2},
\end{gathered}
$$

where $\rho$ is the density of mud, $t$ is the time, $p$ is the pressure, $v$ is the velocity, $g$ is the acceleration of gravity, $\theta$ is the deviation angle, $d$ is the inner diameter of drill string, and $\lambda$ is the traction coefficient. An empirical formula was derived by Blasius:

$$
\lambda=0.3164 \mathrm{Re}^{-0.25},
$$

where Re is the Reynolds number for mud flow in drill string.

In momentum equation (2), external forces affecting mud flow behavior were restricted to gravity and wall shear stresses only.

It is assumed that the effects of thermal conductivity of the fluid are negligible; this allows the pressure and density fluctuations to be isentropic related so that

$$
\frac{\partial p}{\partial t}+v \frac{\partial p}{\partial x}=\frac{\varepsilon}{\rho}\left(\frac{\partial \rho}{\partial t}+v \frac{\partial \rho}{\partial x}\right)
$$

where $\varepsilon$ denotes the bulk modulus of mud.

So far we have described the governing equations of mud flow. These equations are nonlinear. Linear perturbation analysis was applied to derive governing equations of oscillatory motion aroused by incident mud pulse. We assume that the state variables $v, p$, and $\rho$ are perturbed from their state values by some small amount. The motion of the particle due to its oscillation in the mud pulse may be completely decoupled from its gross motion. Hence, our state variables can be denoted collectively by

$$
f=f_{0}+f^{\prime}
$$

where subscript " 0 " and prime "'l" denote the time-averaged state and the oscillating state.

The linearized perturbation equations are (to first order in the perturbed variables)

$$
\begin{gathered}
\frac{\partial \rho^{\prime}}{\partial t}+\rho_{0} \frac{\partial v^{\prime}}{\partial x}+v_{0} \frac{\partial \rho^{\prime}}{\partial x}=0 \\
\rho_{0} \frac{\partial v^{\prime}}{\partial t}+\rho_{0} v_{0} \frac{\partial v^{\prime}}{\partial x}=-\frac{\partial \rho^{\prime}}{\partial x}-\rho^{\prime} g \sin \theta-\frac{\lambda}{d} v_{0} v^{\prime}, \\
\frac{\partial \rho^{\prime}}{\partial t}+v_{0} \frac{\partial \rho^{\prime}}{\partial x}=\frac{\varepsilon}{\rho_{0}}\left(\frac{\partial \rho^{\prime}}{\partial t}+v_{0} \frac{\partial \rho^{\prime}}{\partial x}\right) .
\end{gathered}
$$

We obtained governing equations of oscillating motion as the above. Essentially, these linearized equations constitute the mathematical model of mud pulse propagation in drill string. However, in the momentum equation (7), molecular interactions between adjacent flow layers were neglected. It is out of character to use such simplification for mud, a typical viscous medium. Inevitably, viscous dissipation generated by oscillatory motion between adjacent layers in mud a viscous system gives rise to the attenuation of mud pulse. In a standard text, the momentum conservation equation for the oscillatory motion of fluid particle between adjacent layers was given in the following manner:

$$
\rho_{0} \frac{\partial v^{\prime}}{\partial t}+\rho_{0} v_{0} \frac{\partial v^{\prime}}{\partial x}=-\frac{\partial p^{\prime}}{\partial x}-\frac{2}{d} \sqrt{2 \mu \rho_{0} \omega} v^{\prime}
$$

where $\omega$ is the angular frequency of mud pulse.

Combination of (7) and (9) yields the complete momentum equation for mud pulse propagation in drill string:

$\rho_{0} \frac{\partial v^{\prime}}{\partial t}+\rho_{0} v_{0} \frac{\partial v^{\prime}}{\partial x}=-\frac{\partial p^{\prime}}{\partial x}-p^{\prime} g \sin \theta-\frac{\lambda}{d} v_{0} v^{\prime}-\frac{2}{d} \sqrt{2 \mu \rho_{0} \omega} v^{\prime}$.

A complete set of linearized equations has now been developed, and their limits of validity have clearly been investigated. Continuity is imposed by (6), with the equation of state (8), allowing for the compressibility of mud fluid. Linearized momentum is conserved by (10), which describes the momentum interactions associated with wall shear stresses, gravity, and oscillatory motion between adjacent layers. In the following, these equations are analytically solved, and travelling mud pulse solutions are presented in terms of wave speed and attenuation coefficients.

2.2. Solving Linearized Equations. We seek wave-like solutions to these equations of the form

$$
f^{\prime}=f_{0} e^{i(\omega t-k x)}
$$

where

$$
k=\frac{\omega}{c}+i \eta
$$

where $k$ is wave number of mud pulse in drill string, $c$ is the wave speed, and $\eta$ is the attenuation coefficient. 
Substituting the perturbed variable into the full equations and omitting minute terms, the following equations were obtained, respectively:

$$
\begin{gathered}
\left(\omega-v_{0} k\right) \rho^{\prime}-\rho_{0} k v^{\prime}=0 \\
{\left[i\left(\frac{\lambda v_{0}}{d}+\frac{2}{d \rho_{0}} \sqrt{2 \mu \rho_{0} \omega}\right)-\omega\right] v^{\prime}+\frac{k}{\rho_{0}} p^{\prime}+i \frac{g \sin \theta}{\rho_{0}} \rho^{\prime}=0} \\
\rho_{0} p^{\prime}-\varepsilon p^{\prime}=0 .
\end{gathered}
$$

The above equations can be regarded as a system of linear homogeneous first-order equations in three unknowns: $\rho^{\prime}, p^{\prime}$, and $v^{\prime}$. Under low Mach number, we have the approximation $\omega-k v \approx \omega$. Hence these equations have a nontrivial solution if and only if

$$
\left[\begin{array}{ccc}
\omega & -\rho_{0} k & 0 \\
i \frac{g \sin \theta}{\rho_{0}} & i\left(\frac{\lambda v_{0}}{d}+\frac{2}{d \rho_{0}} \sqrt{2 \mu \rho_{0} \omega}\right)-\omega & \frac{k}{\rho_{0}} \\
-\varepsilon & 0 & \rho_{0}
\end{array}\right]=0
$$

which in turn implies that

$$
\begin{aligned}
k^{2}+ & i \frac{\rho_{0} g \sin \theta}{\varepsilon} k \\
& +\frac{1}{\varepsilon}\left[-\rho_{0} \omega+i\left(\frac{\lambda v_{0} \rho_{0} \omega}{d}+\frac{2 \omega}{d} \sqrt{2 \mu \rho_{0} \omega}\right)\right]=0 .
\end{aligned}
$$

The wave speed and attenuation coefficients of mud pulse in drilling are given, respectively, by

$$
\begin{aligned}
& c=\frac{\omega}{|R(k)|} \\
&=\frac{\omega}{\sqrt{\rho_{0} / 2 \varepsilon}}\left[\left(\omega^{2}-\frac{\rho_{0} g^{2} \sin ^{2} \theta}{4 \varepsilon}\right)\right. \\
&+\left[\left(\omega^{2}-\frac{\rho_{0} g^{2} \sin ^{2} \theta}{4 \varepsilon}\right)^{2}\right. \\
&\left.\left.+\left(\frac{\lambda v_{0} \omega}{d}+\frac{2 \omega}{d} \sqrt{\frac{2 \mu \omega}{\rho_{0}}}\right)^{2}\right]^{1 / 2}\right]^{-(1 / 2)},
\end{aligned}
$$

$$
\begin{aligned}
\eta=|\operatorname{Im}(k)| & \sqrt{\frac{\rho_{0}}{2 \varepsilon}}[ \\
\qquad & {\left[\frac{\lambda v_{0} \omega}{d}+\frac{2 \omega}{d} \sqrt{\frac{2 \mu \omega}{\rho_{0}}}\right)^{2} } \\
& \left.+\left(\omega^{2}-\frac{\rho_{0} g^{2} \sin ^{2} \theta}{4 \varepsilon}\right)^{2}\right]^{1 / 2} \\
& \left.-\left(\omega^{2}-\frac{\rho_{0} g^{2} \sin ^{2} \theta}{4 \varepsilon}\right)\right]^{1 / 2}-\frac{\rho_{0} g \sin \theta}{2 \varepsilon}
\end{aligned}
$$

where $R(k)$ is the real part of wave number $k$ and $\operatorname{Im}(k)$ is the imaginary part.

Hereunto, we have derived formulas used to compute the wave speed and attenuation coefficients of mud pulse in drilling. The static state density of mud $\rho_{0}$ is a key sensitive parameter in the authors' formulas. In general, the static state density $\rho_{0}$ is deemed to be invariable $[7,8]$. For the conditions of interest, where the temperature and pressure of mud flow behave in an extremely high mode, mud density cannot be regarded as numeric constant. Hence, the density behavior of mud in high temperature high pressure environments has to be discussed in this paper.

2.3. Density Behavior of Mud. It has been found experimentally that the density fluctuation in drilling is nonmonotonic with respect to the depth of interest. As the pressure and temperature of mud column increase in depth, the mud experiences two opposing effects. Increase in pressure tends to increase the mud density due to compressibility, while the increase in temperature tends to decrease the mud density due to thermal expansion. Karstad and Aadnoy [43] studied the density behavior of mud during high pressure high temperature drilling operations. A more accurate analytical model for density-pressure-temperature dependence for mud in drilling was presented in the following manner:

$$
\rho=\rho_{\mathrm{sf}} e^{\Gamma\left(\rho_{0}, T\right)},
$$

where $\rho_{\text {sf }}$ is the static state density of mud fluid at surface conditions, $T$ is the temperature of interest, the coefficient $\Gamma\left(p_{0}, T\right)$ is given by

$$
\begin{aligned}
\Gamma\left(p_{0}, T\right)= & \gamma_{p}\left(p_{0}-p_{\mathrm{sf}}\right)+\gamma_{p p}\left(p_{0}-p_{\mathrm{sf}}\right)^{2} \\
& +\gamma_{T}\left(T-T_{\mathrm{sf}}\right)^{2}+\gamma_{T T}\left(T-T_{\mathrm{sf}}\right)^{2} \\
& +\gamma_{p T}\left(p_{0}-p_{\mathrm{sf}}\right)\left(T-T_{\mathrm{sf}}\right),
\end{aligned}
$$

and $T_{\text {sf }}$ is the temperature of mud fluid at surface conditions

The values of $\gamma_{p}, \gamma_{p p}, \gamma_{T}, \gamma_{T T}$, and $\gamma_{p T}$ are essentially unknown and must be determined for different muds from density measurements at elevated pressures and temperatures. The constants for some different muds have been measured by Peters et al. [44] and Isambourg et al. [42].

Estimation of temperature of mud down drill string is also required to ascertain the mud density. Many efforts have 
been made to calculate mud temperature in wellbore $[45,46]$. Kabir et al. [46] presented a simple and available analytical model for calculating circulating mud fluid temperature; the expression is given by

$$
\begin{gathered}
T\left(z, t_{c}\right)=\varphi e^{\xi_{1} z}+\delta e^{\xi_{2} z}+g_{\mathrm{G}} z-A g_{\mathrm{G}}+T_{\mathrm{es}}, \\
A=\frac{c_{\mathrm{fl}} w}{2 \pi r_{d} U_{d}},
\end{gathered}
$$

where $z$ is the wellbore depth of interest, $t_{c}$ is the circulation time, $T_{\text {es }}$ is the surface temperature of earth, $c_{\mathrm{fl}}$ is the heat capacity of mud fluid, $w$ is the mass flow rate of mud fluid, $r_{d}$ is the radius of drill string, $U_{d}$ is the overall heat-transfer coefficient in drill string, and $g_{\mathrm{G}}$ is the geothermal gradient. The constants $\varphi, \zeta_{1}, \zeta_{2}$, and $\delta$ are given in the appendix.

\section{Experiments}

3.1. Experimental Apparatus and Method. The experiments conducted to measure pulse velocity and attenuation were performed to verify the mathematic model's veracity. The experimental apparatus consists of fluid supply lines, pressure pulse generator, and a test section, as shown in Figure 2. Circulating fluid used in our experiments is water. The test section was made up of a $50 \mathrm{~mm}$ diameter stainless steel tube $24 \mathrm{~m}$ in length, found to be able to sustain a pressure of $2 \mathrm{MPa}$ without breaking. The flow was circulated by a pumping unit. The water flow was controlled by a variable speed motor and measured by a clip ultrasonic flow meter. The discharge of the piston pumping was limited to $10 \mathrm{~m}^{3} / \mathrm{h}$, although it could deliver a higher capacity to $20 \mathrm{~m}^{3} / \mathrm{h}$. A needle valve was installed at the terminal to control the pressure of test section. Four pressure transducers were fitted along the tube axis at intervals of $7 \mathrm{~m}$ in Figure 2. The pressure transducers have a frequency response of $0.1 \sim 1000 \mathrm{~Hz}$ and a maximum full-scale output error of $0.75 \%$ FSO over the 0 to $70^{\circ} \mathrm{C}$ compensated range. Each of them was attached to an oscilloscope and a data recorder. At the top of the test section there was a water plenum (box with $1 \mathrm{~m}$ radius, $2 \mathrm{~m}$ height) which was open to the atmosphere.

A pressure pulse can be generated in the system by means of an extra outlet pipe placed behind the flow meter at the head end of the test section, connected to a fastopening magnetic valve. Both the closing and opening times of the magnetic valve can be controlled in steps of $1 \mathrm{~ms}$. The generated pressure pulse was measured by four pressure transducers and the signal from which was captured by oscilloscope and then recorded by a data recorder.

The typical pressure pulses with a step-like form, generated by fast-opening magnetic valve and recorded by a digital oscilloscope, were given in Figure 3. It was noted that the pressure pulses appeared at the upper transducer station of Figure 2 exhibited some attenuation as they passed the lower transducer station, with little distortion of pulse shape observed.

The pulse speed and attenuation coefficient measurements were made using a time of flight method. The node where pressure swoops down was chosen as the discrete time future of each pulse. With the nodes chosen in curve lines, the time of pressure pulse traveling from upper transducer station to the lower one can be read out in Figure 3. The digital oscilloscope in our experiments has two channels, which means that it can capture simultaneously two pressure pulse signals measured by upper and lower pressure transducers. This ensures the reliability of the time measured above. In order to investigate the instant of time at which the pressure waves pass through the measurement section, the wavelet analysis technique proposed by Ferrante et al. [47, 48] was also used in this paper. Similarly, it is easy to determine the amplitude of each pressure pulse. With the known distance between two transducer stations, the pulse speed and attenuation coefficients can be given, respectively, as follows:

$$
c=\frac{\Delta l}{\Delta t},
$$

where $\Delta t$ is the time pressure travelling from upper transducer station to the lower one and $\Delta l$ is the distance between two transducer station,

$$
\eta=\frac{\ln \left(N_{\text {upper }} / N_{\text {lower }}\right)}{\Delta l},
$$

where the nomenclature $N$ is the amplitude of pressure pulse and subscripts "upper" and "lower" denote, respectively, the upper transducer and lower transducer.

3.2. Comparison of Analysis and Experimental Results. The wave speed of pressure pulse calculated by using the present model is compared in Figure 4 with the experimental data. Similarly, a comparison of the attenuation coefficient between calculated and the tested one is shown in Figure 5. Both comparisons are good, showing that the model has the capability of predicting the propagation and attenuation phenomena of pressure pulse. Note that the wave speed and attenuation coefficients are almost constant regardless of the static pressure through the pressure range of $0.15-$ $0.8 \mathrm{MPa}$. The results agree with the experimental results reported in the past as well. In our analytical model, the static pressure plays a role in the value of wave speed and attenuation by affecting the static state fluid density. The effect of fluid density behavior due to compression and thermal expansion on pressure pulse propagation and attenuation is considered in this paper, and the density fluctuations are too minute to affect the speed and attenuation profiles in our experiments with a constant temperature and a very puny static pressure change for $0.65 \mathrm{MPa}$. This gives a theoretical explanation for the experimental phenomena that the wave speed and attenuation are almost constant with changing static pressure. For high temperature deep well drilling, where the circulating mud may reach $450 \mathrm{~K}$ in temperature and $100 \mathrm{MPa}$ in pressure, the effect of density behavior is not minute any more but large enough to change the speed and attenuation profiles of mud pulse.

\section{Results and Discussion}

The model is able to predict the propagation and attenuation of mud pulse in drilling. It is absolutely essential to discuss 


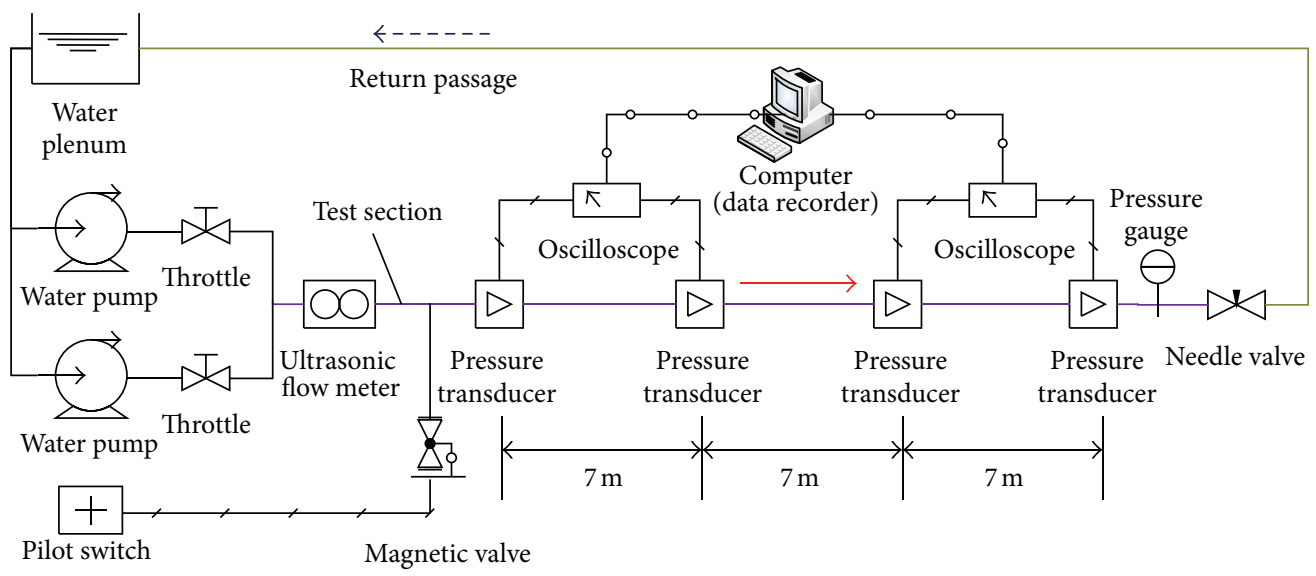

FIgURE 2: Experimental apparatus.

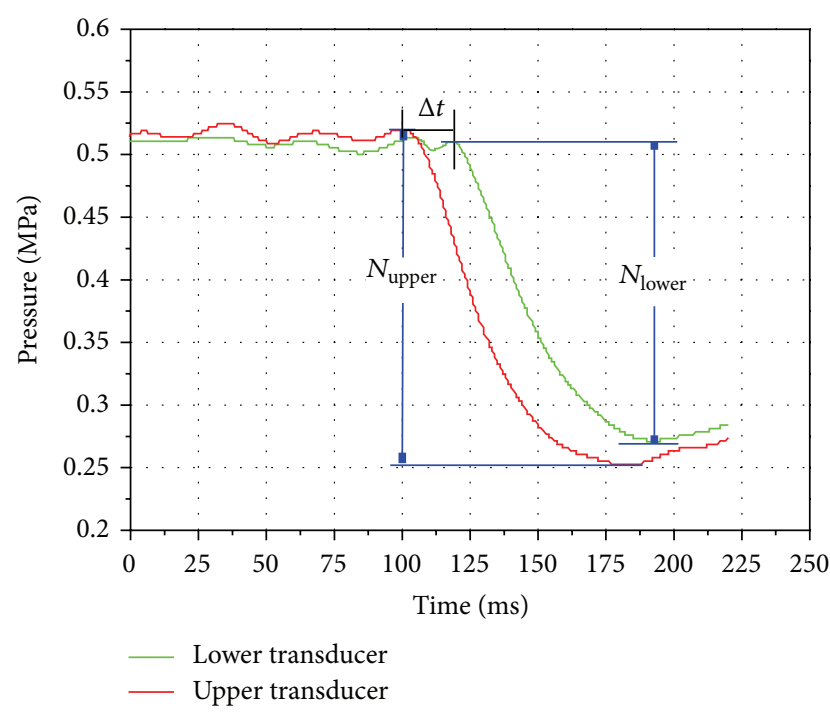

FIgURE 3: Pressure pulse waveforms from two transducers.

the effects of major sensitive variables on the propagation and attenuation of mud pulse. Data of a water-base mud from Isambourg et al. [42] reproduced in Table 1 are used here to calculate the analytical solution.

4.1. Influences of Angular Frequency. The wave speed and attenuation coefficients of mud pulse in drill string were calculated by (16) and (17), respectively. In order to focus on the effect of the angular frequency, we eliminated the effects of mud density behavior and mud viscosity by fixing the static density at $2212 \mathrm{~kg} \cdot \mathrm{m}^{-3}$, plastic viscosity at $20 \mathrm{mPa} \cdot \mathrm{s}$, and static velocity at $2 \mathrm{~m} \cdot \mathrm{s}^{-1}$ in the analyses presented in this section. The deviation angle and inner diameter of tube are assumed to be $0 \mathrm{rad}$ and $0.078 \mathrm{~m}$, respectively.

The computed propagation speed is shown in Figure 6 for a range of angular frequencies. This figure clearly shows that the wave speed increases monotonically with increasing angular frequency at low frequencies and approaches a constant value at high frequencies. The demarcation between

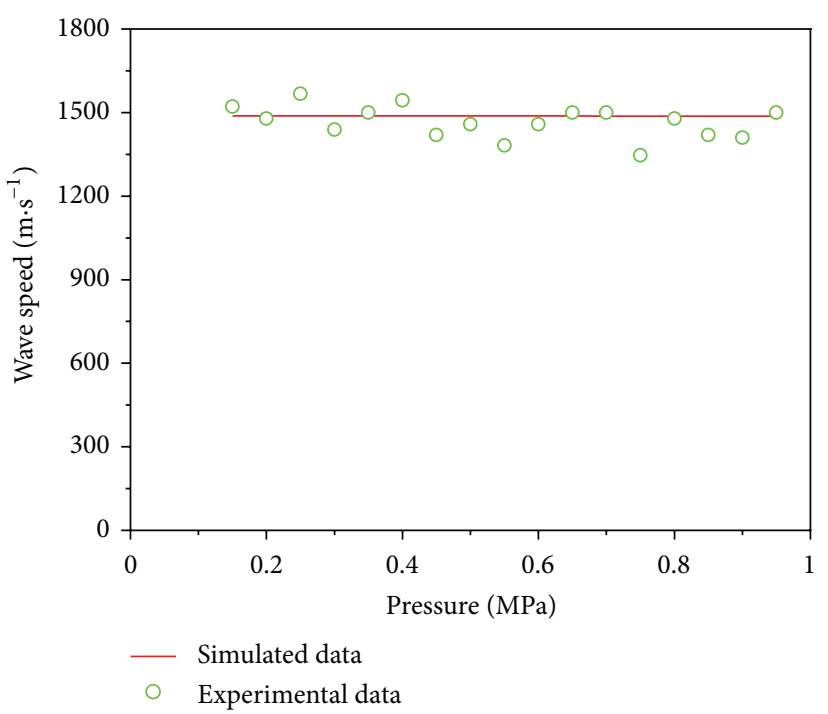

FIgURE 4: Comparison of simulated and experimental wave speed of pressure pulse for $v_{0}=0.81 \mathrm{~m} \cdot \mathrm{s}^{-1}$, and $\omega=25 \mathrm{~Hz}$.

the two regimes can be drawn at $\omega \sim 30$ in Figure 6. The high frequency limit for the wave speed as predicted by (16) is given by

$$
\lim _{\omega \rightarrow \infty} c=\sqrt{\frac{\varepsilon}{\rho_{0}}}
$$

which is entirely independent of the frequency other than the mud static density and compressibility. Equation (24) is also the traditional phenomenological model for pressure wave speed. That is, the traditional phenomenological model is a special case in high frequency of the wave speed model proposed in this paper. In drilling, the frequency of mud pulse is usually less than $24 \mathrm{~Hz}$, and the practices indicate that the wave speed is sensitive to the frequency. In this case, the phenomenological model which is independent of the frequency seems to be inapplicable. By contrast, our wave speed model is more feasible and valuable. The attenuation 
TABLE 1: Empirical constants for the water-base mud (from Isambourg et al. [42]).

\begin{tabular}{lccccccc}
\hline$\rho_{\text {sf }}$ & $\gamma_{p} \cdot 10^{10}$ & $\gamma_{p p} \cdot 10^{19}$ & $\gamma_{T} \cdot 10^{4}$ & $\gamma_{T T} \cdot 10^{7}$ & $\gamma_{p T} \cdot 10^{13}$ & $\mu$ \\
$\mathrm{Kg}^{-3}$ & $\mathrm{~Pa}^{-1}$ & $\mathrm{~Pa}^{-2}$ & $\mathrm{~K}^{-1}$ & $\mathrm{~K}^{-1} \mathrm{~Pa}^{-1}$ & $\begin{array}{c}\mu \\
\mathrm{mPa} \cdot \mathrm{s}\end{array}$ \\
\hline 2212 & 2.977 & -2.293 & -1.957 & -16.838 & 0.686 & 20 & 3.359 \\
\hline
\end{tabular}

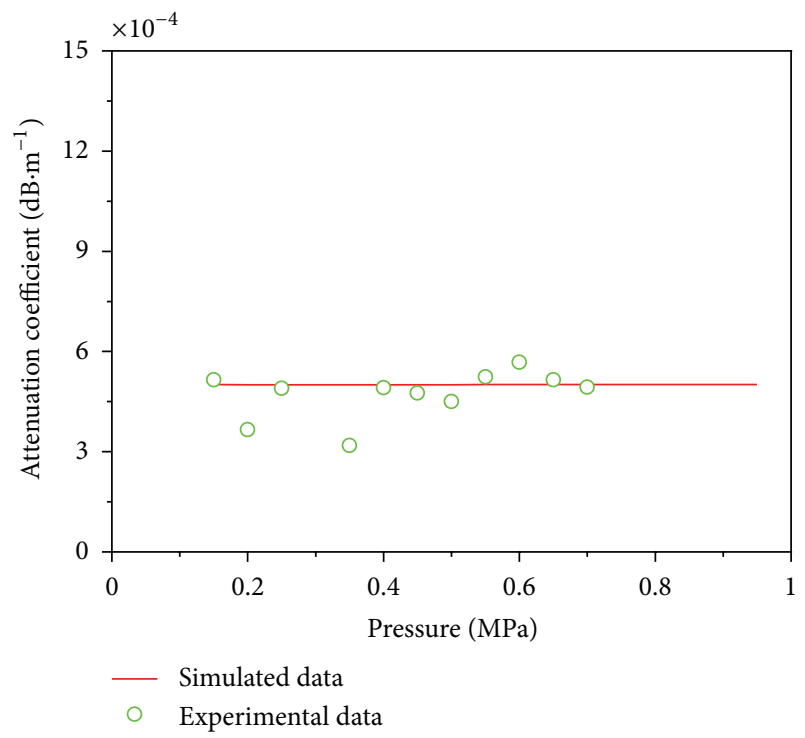

FIGURE 5: Comparison of simulated and experimental attenuation coefficient of pressure pulse for $v_{0}=0.81 \mathrm{~m} \cdot \mathrm{s}^{-1}$, and $\omega=25 \mathrm{~Hz}$.

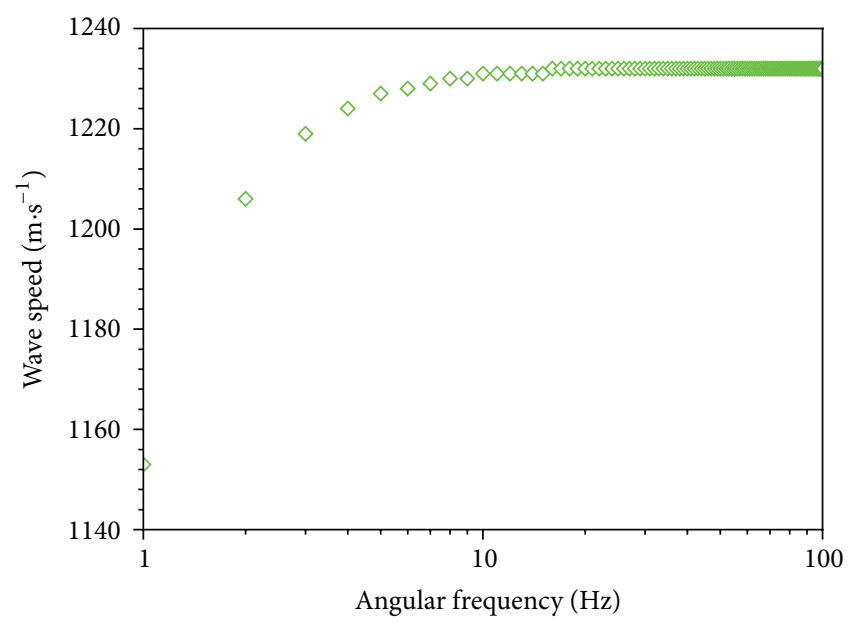

FIGURE 6: Theoretical wave speed as a function of angular frequency for mud.

coefficient predicted by (17), plotted in Figure 7, exhibits a different change trend in slope from that of wave speed. The attenuation coefficient profile does not show a constant value at high frequencies but rather increases monotonically with increasing frequency. Besides, the effect of frequency on attenuation coefficient is seen to be large compared with the speed. This figure also suggests that at low frequencies, good penetration can readily be achieved with mud fluid in

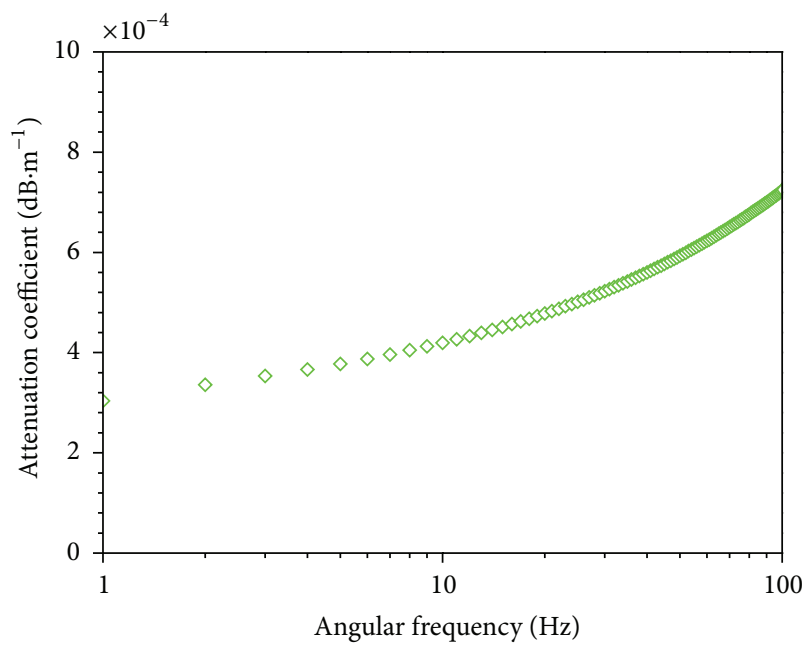

FIGURE 7: Theoretical attenuation coefficient as a function of angular frequency for mud.

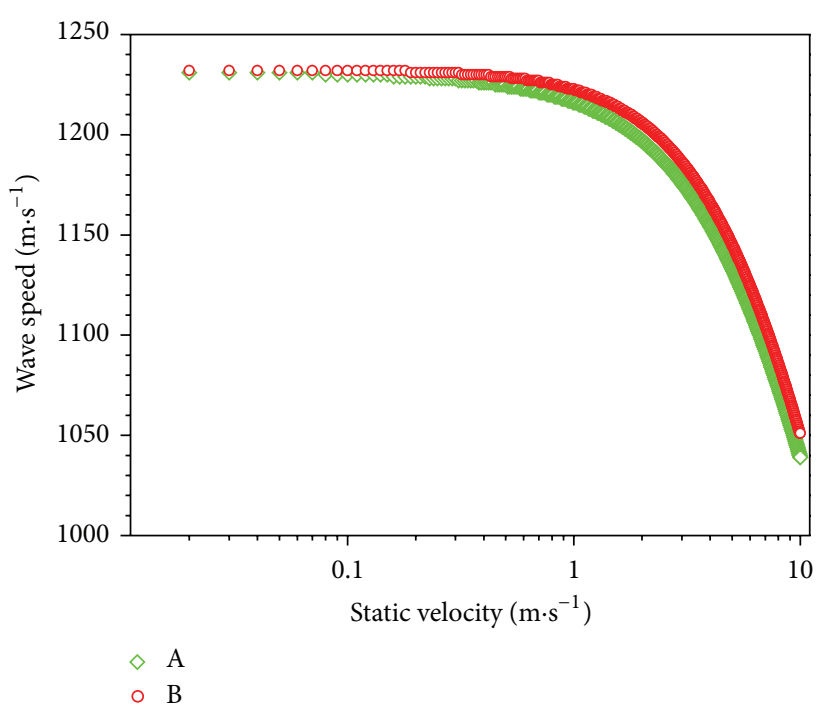

FIGURE 8: Theoretical wave speed as a function of $v_{0}$ at $\omega=1 \mathrm{~Hz}$, and $\mu=20 \mathrm{mPa} \cdot \mathrm{s}$.

drilling, which may contribute to enlightening the design of new MWD core components.

4.2. Influences of Static Velocity and Mud Viscosity. Two primary variables in our solutions are $\mu$ and $v_{0}$, representing the influences of mud viscous and inertia on wave speed and attenuation coefficients, separately. The speed and attenuation coefficients against $v_{0}$ for mud pulse are plotted, respectively, in Figures 8 and 9 as the curve A. In the computations, 


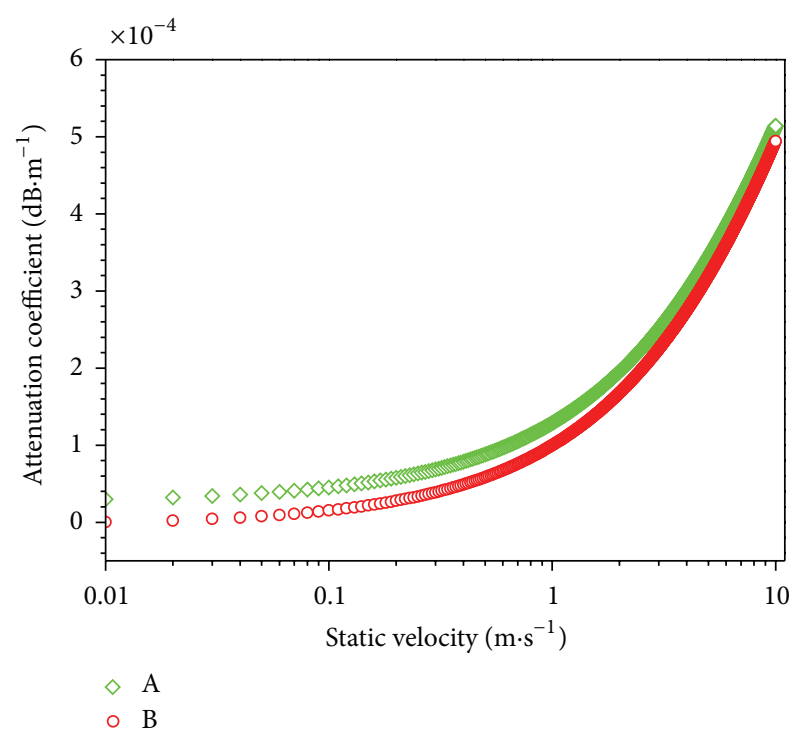

FIgURE 9: Theoretical attenuation coefficient as a function of $v_{0}$ at $\omega$ $=1 \mathrm{~Hz}$, and $\mu=20 \mathrm{mPa} \cdot \mathrm{s}$.

we fixed the angular frequency at $1 \mathrm{~Hz}$, deviation angle at $0 \mathrm{rad}$, and some parameters of mud as shown in Table 1. In order to investigate the influence of viscous oscillatory motion between adjacent layers, the simulated results of mud pulse neglecting this effect are also plotted in Figures 8 and 9 as the curve B. As shown in the graphs, the wave speed decreases with the increase of $v_{0}$, but the attenuation coefficient takes on an inverse tendency. Compared with the speed, the attenuation coefficient curve takes on an obvious variation in magnitude with respect to the static velocity. In general, the influence of viscous oscillation between adjacent layers on propagation speed is seen to be small in comparison with attenuation coefficient, especially in low static velocity. In this paper, the viscous dissipation between adjacent layers in the system which has not been studied before is involved. In drilling operations, a better efficiency of receiving mud pulse signal can be acquired by stopping the mud pumps or lowering circulation velocity. The validity of the operations can be demonstrated theoretically in Figures 8 and 9, which is also a convincing illustration of the valid analytical approach developed here.

The influences of mud viscosity on wave speed and attenuation coefficients of mud pulse are illustrated by Figures 10 and 11, respectively. The figures clearly show that the viscous effect restricts the propagation of mud pulse, while aggravating the pulse attenuation. Consequently, on the premise of satisfying the requirements of carrying cuttings, maintaining the rheology property of mud and other drilling engineering needs to reduce the viscosity of mud benefits alleviating the attenuation of mud pulse and improving the propagation of the measurement signals.

4.3. Wave Speed and Attenuation Coefficient Profiles Affected by Density Behavior. In high temperature deep formation, the mud density influenced by high temperature and high

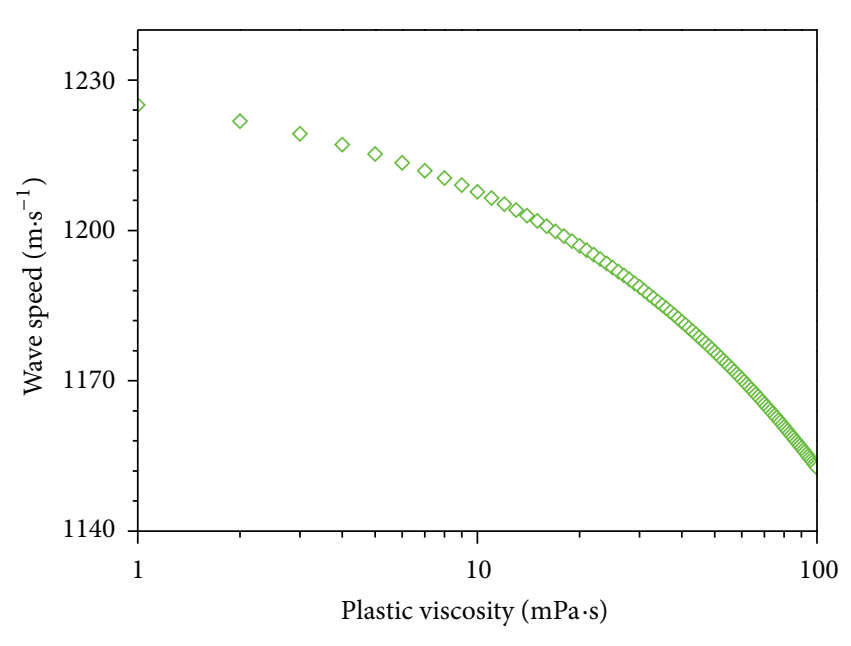

FIgURE 10: Theoretical wave speed as a function of $\mu$ at $\omega=1 \mathrm{~Hz}$, and $v_{0}=2 \mathrm{~m} \cdot \mathrm{s}^{-1}$.

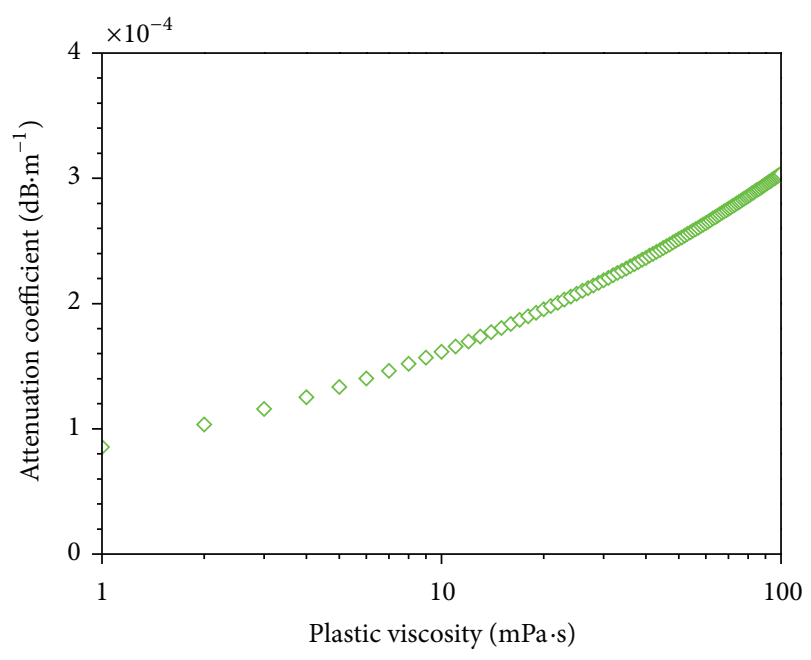

FIgURE 11: Theoretical attenuation coefficient as a function of $\mu$ at $\omega=1 \mathrm{~Hz}$, and $v_{0}=2 \mathrm{~m} \cdot \mathrm{s}^{-1}$.

pressure becomes critical, which has inevitable effects on the mud pulse transmission along the wellbore. In this section, we focus on the influences of density behavior on mud pulse wave speed and attenuation coefficient profiles for different circulation time. Table 2 presents the data used for the calculation. In addition, some data for mud has been shown in Table 1.

The influence of density behavior on wave speed and attenuation coefficient profiles is illustrated by Figures 12 and 13, respectively. The mud density is always in a transient state and varies along the wellbore, strongly sensitive to the pressure and temperature as shown in Figure 14. In our simulation, we consider the wellbore heat transfer during drilling and give the temperature profile for different circulation times illustrated in Figure 15. Accordingly, the pressure profile along the wellbore is also provided in Figure 16. The figures clearly indicate that the wave speed and attenuation 
TABLE 2: Parameters for the calculation of temperature profile.

\begin{tabular}{lccccccccccc}
\hline$H$ & $r_{d}$ & $r_{c}$ & $\begin{array}{c}w \\
\mathrm{~m}\end{array}$ & $\begin{array}{c}g_{\mathrm{G}} \\
\mathrm{mg} \cdot \mathrm{s}^{-1}\end{array}$ & $\begin{array}{c}\mathrm{K}_{\mathrm{sf}} \cdot \mathrm{m}^{-1} \\
\mathrm{~K}\end{array}$ & $\begin{array}{r}T_{\mathrm{di}} \\
\mathrm{K}\end{array}$ & $\begin{array}{r}T_{\mathrm{es}} \\
\mathrm{K}\end{array}$ & $\begin{array}{c}k_{e} \\
\mathrm{~W} \cdot \mathrm{m}^{-1} \cdot \mathrm{K}^{-1}\end{array}$ & $\begin{array}{c}c_{\mathrm{fl}} \\
\mathrm{J} \cdot \mathrm{kg}^{-1} \cdot \mathrm{K}^{-1}\end{array}$ & $\begin{array}{c}U_{a} \\
\mathrm{~W} \cdot \mathrm{m}^{-2} \cdot \mathrm{K}^{-1}\end{array}$ & $\begin{array}{c}U_{d} \\
\mathrm{~W} \cdot \mathrm{m}^{-2} \cdot \mathrm{K}^{-1}\end{array}$ \\
\hline 5000 & 0.078 & 0.089 & 39.816 & 0.03 & 300 & 300 & 300 & 1.44 & 1674.72 & 163.25 & 172.05 \\
\hline
\end{tabular}

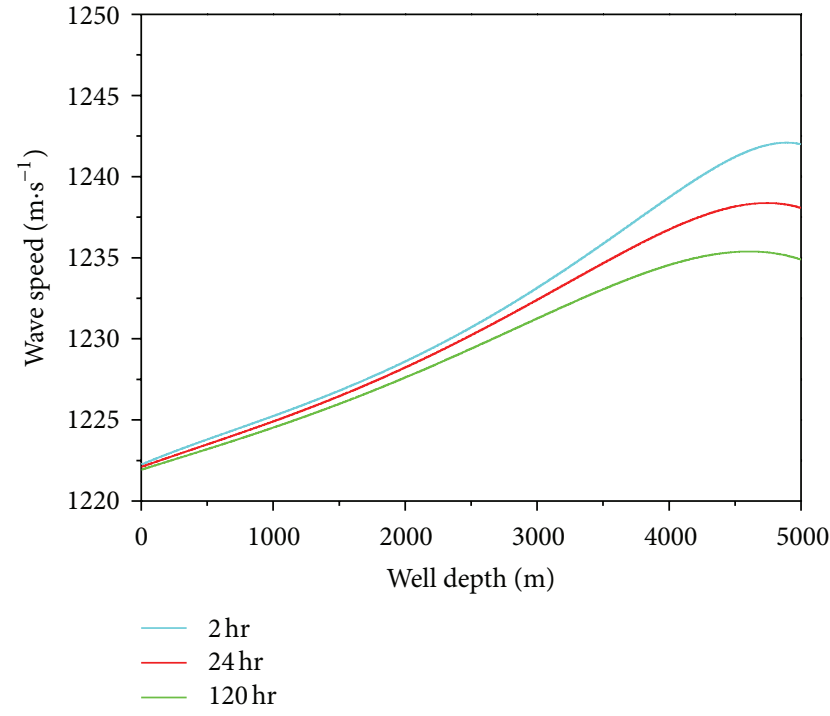

Figure 12: Wave speed profile for different circulation times at $\omega=$ $1 \mathrm{~Hz}$.

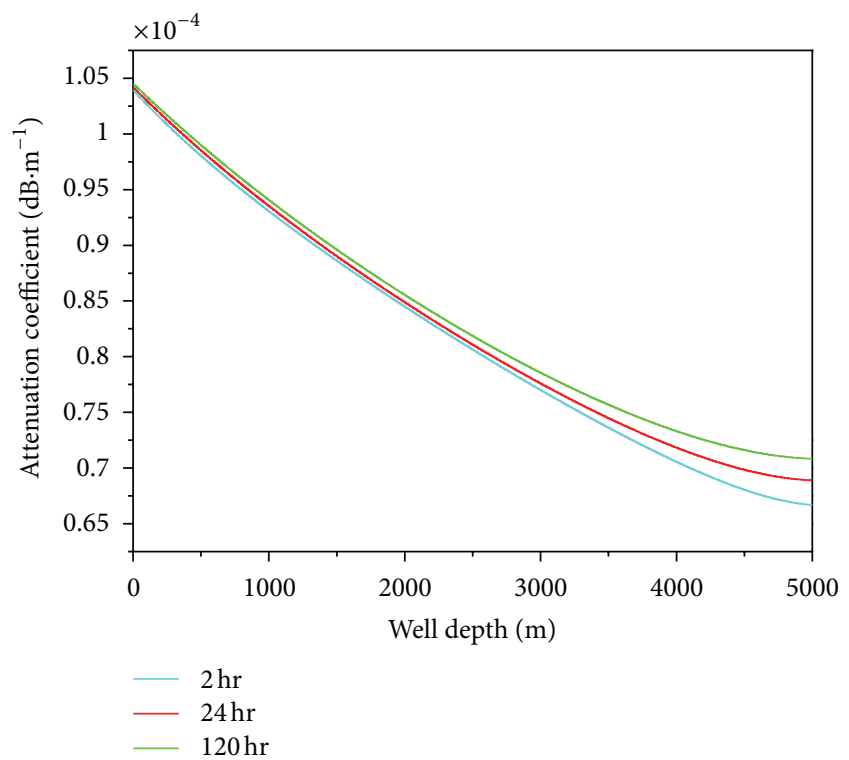

FIGURE 13: Attenuation coefficient profile for different circulation times at $\omega=1 \mathrm{~Hz}$.

coefficients in drill sting are not invariable but show a distinct change with the increase in well depth. Affected by the density behavior, the mud pulse attenuates severer in the upper section of the wellbore. Besides, Figures 12 and 13 also show the differences of speed and attenuation coefficient profiles for different circulation times. With circulating of mud fluid,

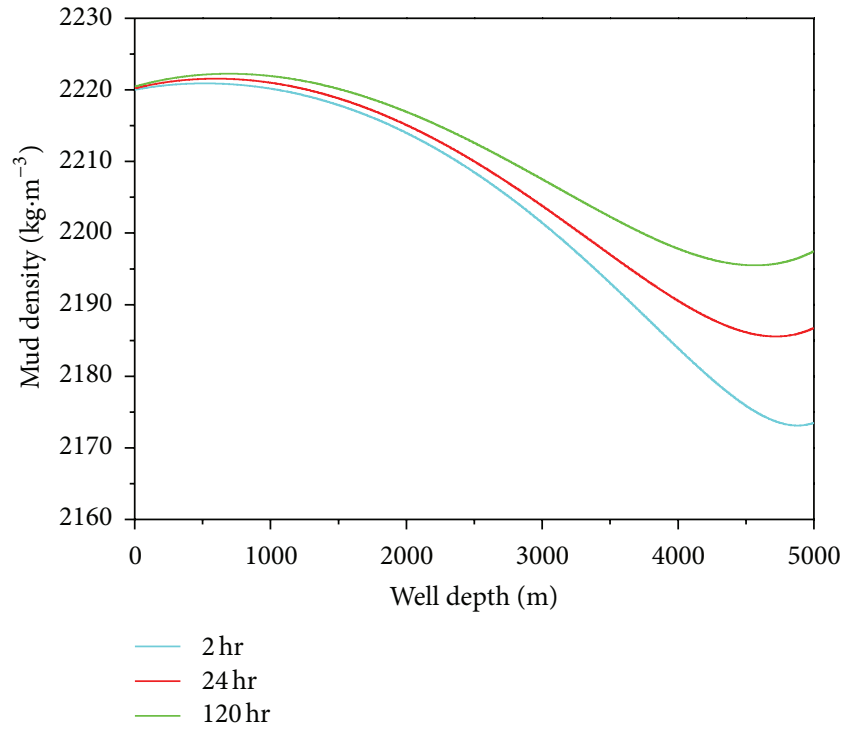

FIGURE 14: Mud density profile for different circulation times at $\omega=$ $1 \mathrm{~Hz}$.

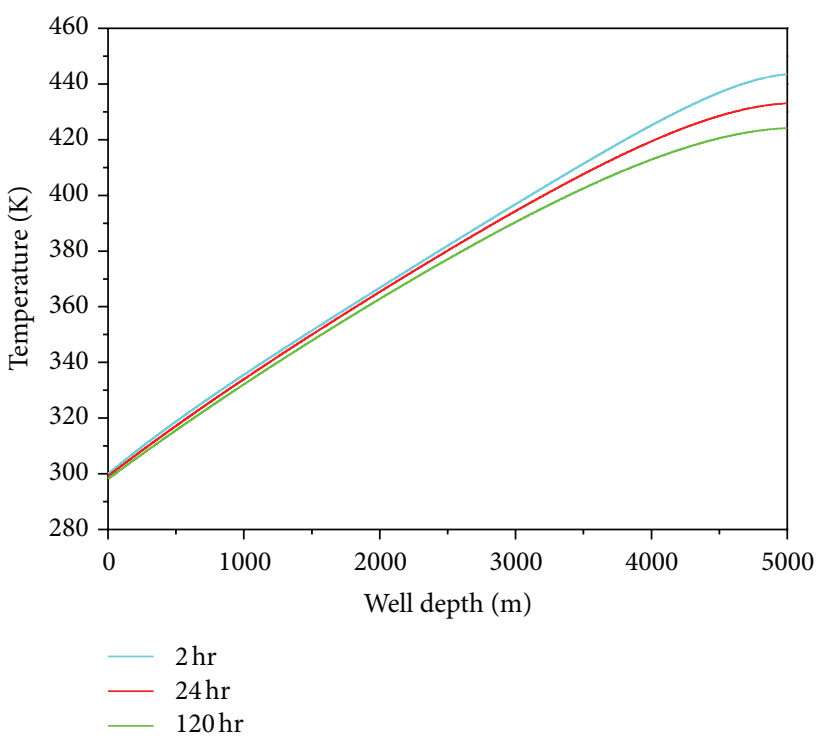

Figure 15: Temperature profile for different circulation times at $\omega=$ $1 \mathrm{~Hz}$.

the pulse propagates with a lower speed and attenuates more and more seriously in lower section of the wellbore. We can explain this phenomenon by inspecting the temperature profile change in Figure 15. Caused by the cooling effect, the rate of heat transfer between the wellbore and the formation diminishes with increasing circulation time. Consequently, 


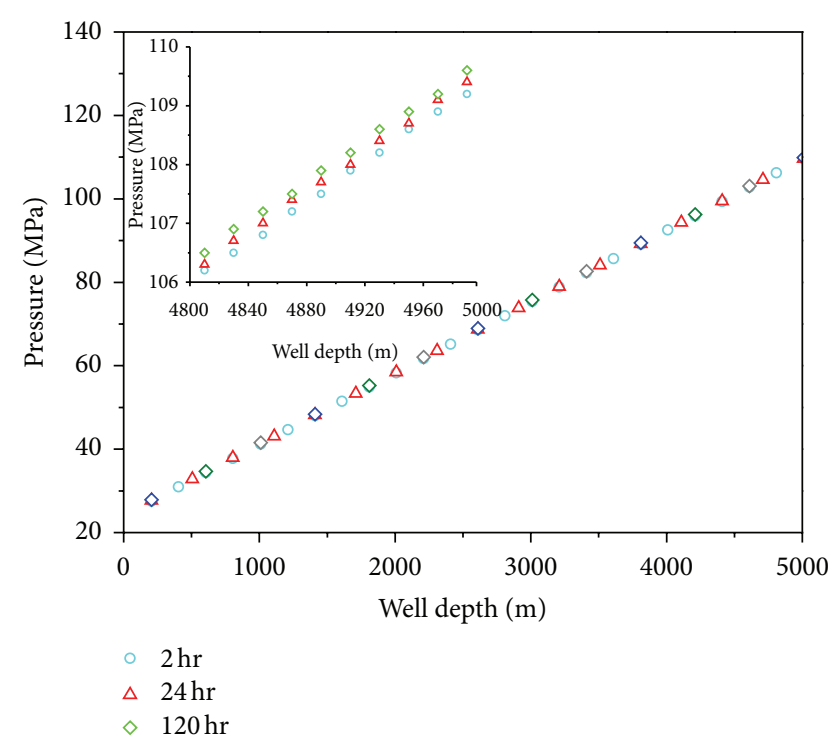

Figure 16: Pressure profile in drill string for different circulation times at $\omega=1 \mathrm{~Hz}$.

the temperature in drill string declines with circulating and engenders eventually the changes of speed and attenuation coefficient profiles.

\section{Conclusion}

In this study, an analytical model has been developed for the study of mud pulse propagation and attenuation through the drill string in high temperature deep well drilling. The model formulation takes account of wall shear stresses, gravitational effects, and momentum interchange between adjacent layers and assumes transient mud density behavior to be sensitive to pressure and temperature in drilling string. In comparison with experiments, testing data measured show a good agreement with this model. Based on the analytical solutions, the influences of angular frequency, mud viscosity, static velocity, and mud density behavior on mud pulse propagation were discussed and summarized as follows.

(1) The effect of angular frequency on wave speed appears at low frequency, but the attenuation coefficient increases monotonically with increasing frequency.

(2) The wave speed decreases with increasing static velocity, while the attenuation coefficient takes on an inverse tendency. Dissipation due to viscous oscillation plays a prominent role in mud pulse attenuation at low static velocity.

(3) The viscous effect restricts the propagation of mud pulse, aggravating the pulse attenuation.

(4) Influenced by mud density behavior as a function of temperature and pressure, the wave speed and attenuation coefficients change along the wellbore and differ for different circulation times. The profiles of speed and attenuation coefficients behave distinctly different due to the cooling effect with circulating.
(5) For high temperature deep well drilling operation, lower angular frequency, viscosity, and circulation velocity help relieve the attenuation of measurement signals propagated by mud pulse, and longtime circulation makes against the transmission of pulse signals.

\section{Appendix}

Constants of (20), and mud flow down the drill string.

The constants of (20) are given by the following equations:

$$
\begin{array}{r}
\varphi=-\frac{\left(T_{\mathrm{di}}+A g_{\mathrm{G}}-T_{\mathrm{es}}\right) \xi_{2} e^{\xi_{2} H}+g_{\mathrm{G}}}{\xi_{1} e^{\xi_{1} H}-\xi_{2} e^{\xi_{2} H}}, \\
\delta=-\frac{\left(T_{\mathrm{di}}+A g_{\mathrm{G}}-T_{\mathrm{es}}\right) \xi_{1} e^{\xi_{1} H}+g_{\mathrm{G}}}{\xi_{1} e^{\xi_{1} H}-\xi_{2} e^{\xi_{2} H}}, \\
\xi_{1}=\frac{1}{2 B}+\frac{1}{2 B} \sqrt{1+4\left(r_{c} U_{a} T_{D}+k_{e}\right) \frac{r_{d} U_{d}}{r_{c} U_{a} k_{e}}}, \\
\xi_{2}=\frac{1}{2 B}-\frac{1}{2 B} \sqrt{1+4\left(r_{c} U_{a} T_{D}+k_{e}\right) \frac{r_{d} U_{d}}{r_{c} U_{a} k_{e}}},
\end{array}
$$

where

$$
B=\frac{c_{\mathrm{fl}} w}{2 \pi}\left[\frac{k_{e}+r_{c} U_{a} T_{D}}{r_{c} U_{a} k_{e}}\right],
$$

where $T_{D}$ is the dimensionless temperature, and the estimating models used in this work were presented by Hasan and Kabir [49] as

$$
\begin{gathered}
T_{D}=\left(1.1281 \sqrt{t_{D}}\right) \times\left(1-0.3 \sqrt{t_{D}}\right) \quad \text { if } 10^{-10} \leq t_{D} \leq 1.5, \\
T_{D}=\left(0.4063+0.5 \ln t_{D}\right) \times\left(1+\frac{0.6}{t_{D}}\right) \quad \text { if } t_{D}>1.5,
\end{gathered}
$$

where $T_{\mathrm{di}}$ is the initial temperature of mud fluid in drill string, $H$ is the well depth, $r_{c}$ is the radius of casing, $U_{a}$ is the overall heat-transfer coefficient in annulus, and $k_{e}$ is the conductivity of earth.

\section{Acknowledgments}

The authors are grateful for the support of the National Natural Science Foundation of China (Grant nos. 51134004 and 51104124) and Ph.D. Programs Foundation of Ministry of Education of China (Grant no. 20125121110001).

\section{References}

[1] G. Aithoff, "MWD ultrasonic capliper advanced detection techniques," in Proceedings of the SPWLA 39th Annual Logging Symposium, 1998.

[2] R. Hutin, R. W. Tennent, and S. V. Kashikar, "New mud pulse telemetry techniques for deepwater applications and improved real-time data capabilities," in Proceedings of the SPE/IADC Drilling Conference, pp. 73-82, Amsterdam, The Netherlands, March 2001. 
[3] T. I. Waag, T. Torkildsen, P. A. Amundsen, E. Nyrnes, and A. Saasen, "The design of BHA and the placement of magnetometer sensors influence how magnetic azimuth is distorted by the magnetic properties of drilling fluids," SPE Drilling \& Completion, vol. 27, no. 3, pp. 393-406, 2012.

[4] E. Molz, D. Canny, and E. Evans, "Ultrasonic velocity and attenuation measurements in high density drilling muds," in Proceedings of the 39th Annual Logging Symposium, May 1998.

[5] H. Wang, G. H. Priestman, S. B. M. Beck, and R. F. Boucher, "Pressure wave attenuation in an air pipe flow," Journal of Mechanical Engineering, vol. 214, no. 4, pp. 619-632, 2000.

[6] S. J. Chen and J. T. Aumann, "Numerical simulation of MWD pressure pulse transmission," in Proceedings of the SPE Annual Technical Conference and Exhibition, Las Vegas, Nev, USA, 1985.

[7] X. S. Liu, B. Li, and Y. Q. Yue, "Transmission behavior of mudpressure pulse along well bore," Journal of Hydrodynamics, vol. 19, no. 2, pp. 236-240, 2007.

[8] H. Li, G. Li, Y. Meng, G. Shu, K. Zhu, and X. Xu, "Attenuation law of MWD pulses in aerated drilling," Petroleum Exploration and Development, vol. 39, no. 2, pp. 250-255, 2012.

[9] S. M. Beck, H. Haider, and R. F. Boucher, "Transmission line modelling of simulated drill strings undergoing waterhammer," Journal of Mechanical Engineering Science, vol. 209, no. 6, pp. 419-427, 1995.

[10] A. R. D. Thorley, Fluid Transients in Pipeline Systems, D. and L. George Limited, Batnet, Hertfordshire, UK, 1971.

[11] E. B. Wylie and V. L. Streeter, Fluid Transients, FEB Press, Ann Arbor, Mich, USA, 1983.

[12] R. C. Binder, Advanced Fluid Mechanics, Prentice Hall, Englewood Cliffs, NJ, USA, 1958.

[13] J. Lighthill, Waves in Fluids, Cambridge University Press, Cambridge, UK, 1978.

[14] F. T. Brown, "The transient response of fluid lines," Journal of Fluids Engineering, Transactions of the ASME, vol. 84, no. 4, pp. 547-553, 1962.

[15] A. S. Iberall, "Atttenuation of oscillatory pressures in instrument lines," Journal of Research of the National Bureau of Standards, vol. 45, RP 2115, pp. 85-108, 1950.

[16] N. B. Nichols, "The linear properties of pneumatic transmission lines," ISA Transactions, vol. 1, no. 1, pp. 23-32, 1962.

[17] D. A. P. Jayasinghe, M. S. Letelier, and H. J. Leutheusser, "Frequency-dependent friction in oscillatory laminar pipe flow," International Journal of Mechanical Sciences, vol. 16, no. 11, pp. 819-827, 1974.

[18] W. Zielke, "Frequency-dependent-friction in transient pipe flow," Journal of Fluids Engineering, Transactions of the ASME, vol. 90, no. 1, pp. 109-115, 1968.

[19] K. Suzuki, T. Taketomi, and S. Sato, "Improving Zielke's method of simulating frequency-dependent friction in laminar liquid pipe flow," Journal of Fluids Engineering, Transactions of the ASME, vol. 113, no. 4, pp. 569-573, 1991.

[20] M. C. P. Brunelli, "Two-dimensional pipe model for laminar flow," Journal of Fluids Engineering, Transactions of the ASME, vol. 127, no. 3, pp. 431-437, 2005.

[21] V. P. Kuznetsov, "Equations of nonlinear acoustics," Soviet Physics. Acoustics, vol. 16, pp. 467-470, 1971.

[22] D. T. Blackstock, "Propagation of plane sound waves of finite amplitude in nondissipative fluids," Journal of the Acoustical Society of America, vol. 34, pp. 9-30, 1962.
[23] W. Chester, "Acoustic resonance in spherically symmetric waves," Proceedings of the Royal Society A, vol. 434, pp. 459-463, 1991.

[24] P. E. Doak and P. G. Vaidya, "Attenuation of plane wave and higher order mode sound propagation in lined ducts," Journal of Sound and Vibration, vol. 12, no. 2, pp. 201-224, 1970.

[25] W. Eversman, "Approximation for thin boundary layers in the sheared flow duct transmission problem," Journal of the Acoustical Society of America, vol. 53, no. 5, pp. 1346-1350, 1973.

[26] S. H. Ko, "Theoretical prediction of sound attenuation in acoustically lined annular ducts in the presence of uniform flow and shear flow," Journal of the Acoustical Society of America, vol. 54, no. 6, pp. 1592-1606, 1973.

[27] S. D. Savkar, "Propagation of sound in ducts with shear flow," Journal of Sound and Vibration, vol. 19, no. 3, pp. 355-372, 1971.

[28] P. N. Shankar, "Sound propagation in duct shear layers," Journal of Sound and Vibration, vol. 22, no. 2, pp. 221-232, 1972.

[29] M. N. Mikhail and A. N. Abdelhamid, "Transmission and far field radiation of sound waves in and from lined ducts containing shear flow," AIAA Paper No. 73-1013, 1973.

[30] P. N. Shankar, "Acoustic refraction and attenuation in cylindrical and annular ducts," Journal of Sound and Vibration, vol. 22, no. 2, pp. 233-246, 1972.

[31] W. Eversman, "The effect of boundary layer on the transmission and attenuation of sound in an acoustically treated circular duct," Journal of the Acoustical Society of America, vol. 49, no. 5, pp. 1572-1580, 1971.

[32] W. Eversman, "Representation of a 1/Nth power law boundary layer in the sheared flow acoustic transmission problem," Journal of Sound and Vibration, vol. 24, no. 4, pp. 459-469, 1972.

[33] N. K. Agarwal and M. K. Bull, "Acoustic wave propagation in a pipe with fully developed turbulent flow," Journal of Sound and Vibration, vol. 132, no. 2, pp. 275-298, 1989.

[34] D. M. Auslander, Frequency response of fluid lines with turbulent flow [SM thesis], Engineering Projects Laboratory, Massachusetts Institute of Technology, 1964.

[35] B. Brunone, U. M. Golia, and M. Greco, "Effects of twodimensionality on pipe transients modeling," Journal of Hydraulic Engineering, vol. 121, no. 12, pp. 906-912, 1995.

[36] B. Brunone, B. W. Karney, M. Mecarelli, and M. Ferrante, "Velocity profiles and unsteady pipe friction in transient flow," Journal of Water Resources Planning and Management, vol. 126, no. 4, pp. 236-244, 2000.

[37] F. T. Brown, D. L. Margolis, and R. P. Shah, "Small amplitude frequency behavior of fluid lines with turbulent flow," Journal of Fluids Engineering, vol. 91, no. 4, pp. 678-693, 1969.

[38] A. K. Mitra and W. T. Rouleau, "Radial and axial variations in transient pressure waves transmitted through liquid transmission lines," Journal of Fluids Engineering, Transactions of ASME, vol. 107, no. 1, pp. 105-111, 1985.

[39] S. Stuckenbruck, D. C. Wiggert, and R. S. Otwell, "The influence of pipe motion on acoustic wave propagation," Journal of Fluids Engineering, Transactions of the ASME, vol. 107, no. 4, pp. 518522,1985

[40] Y. Sato and H. Kanki, "Formulas for compression wave and oscillating flow in circular pipe," Applied Acoustics, vol. 69, no. 1, pp. 1-11, 2008.

[41] Y. Sato and H. Kanki, "Simplification of formulas for compression wave and oscillating flow in circular pipe," Applied Acoustics, vol. 69, no. 10, pp. 901-912, 2008. 
[42] P. Isambourg, B. T. Anfinsen, and C. Marken, "Volumetric behavior of drilling muds at high pressure and high temperature," in Proceedings of the European Petroleum Conference, pp. 157-165, October 1996.

[43] E. Karstad and B. S. Aadnoy, "Density behavior of drilling fluids during high pressure high temperature drilling operations," in Proceedings of the IADC/SPE Asia Pacific Drilling Technology, Jakarta, Indonesia, 1998.

[44] E. J. Peters, M. E. Chenevert, and C. Zhang, "Model for predicting the density of oil-based muds at high pressures and temperatures," SPE Drilling Engineering, vol. 5, no. 2, pp. 141148, 1990.

[45] A. R. Hasan and C. S. Kabir, "Wellbore heat-transfer modeling and applications," Journal of Petroleum Science and Engineering, vol. 86-87, pp. 127-136, 2012.

[46] C. S. Kabir, A. R. Hasan, G. E. Kouba, and M. M. Ameen, "Determining circulating fluid temperature in drilling, workover, and well-control operations," SPE Drilling and Completion, vol. 11, no. 2, pp. 74-78, 1996.

[47] M. Ferrante, B. Brunone, and S. Meniconi, "Wavelets for the analysis of transient pressure signals for leak detection," Journal of Hydraulic Engineering, vol. 133, no. 11, pp. 1274-1282, 2007.

[48] M. Ferrante, B. Brunone, and S. Meniconi, "Leak detection in branched pipe systems coupling wavelet analysis and a Lagrangian model," Journal of Water Supply, vol. 58, no. 2, pp. 95-106, 2009.

[49] A. R. Hasan and C. S. Kabir, "Aspects of wellbore heat transfer during two-phase flow," SPE Production \& Facilities, vol. 9, no. 3, pp. 211-216, 1994. 


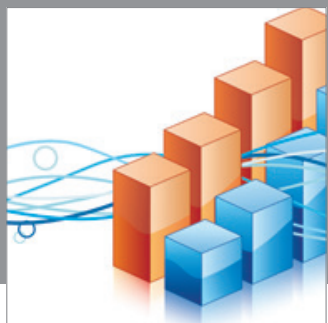

Advances in

Operations Research

mansans

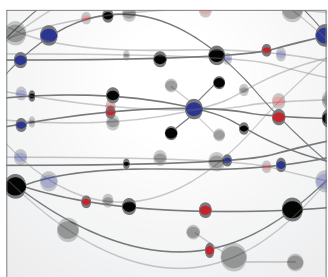

The Scientific World Journal
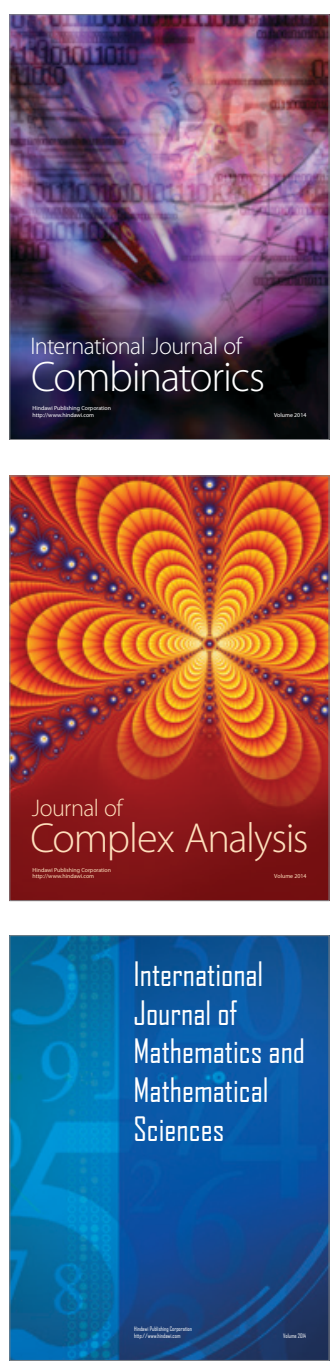
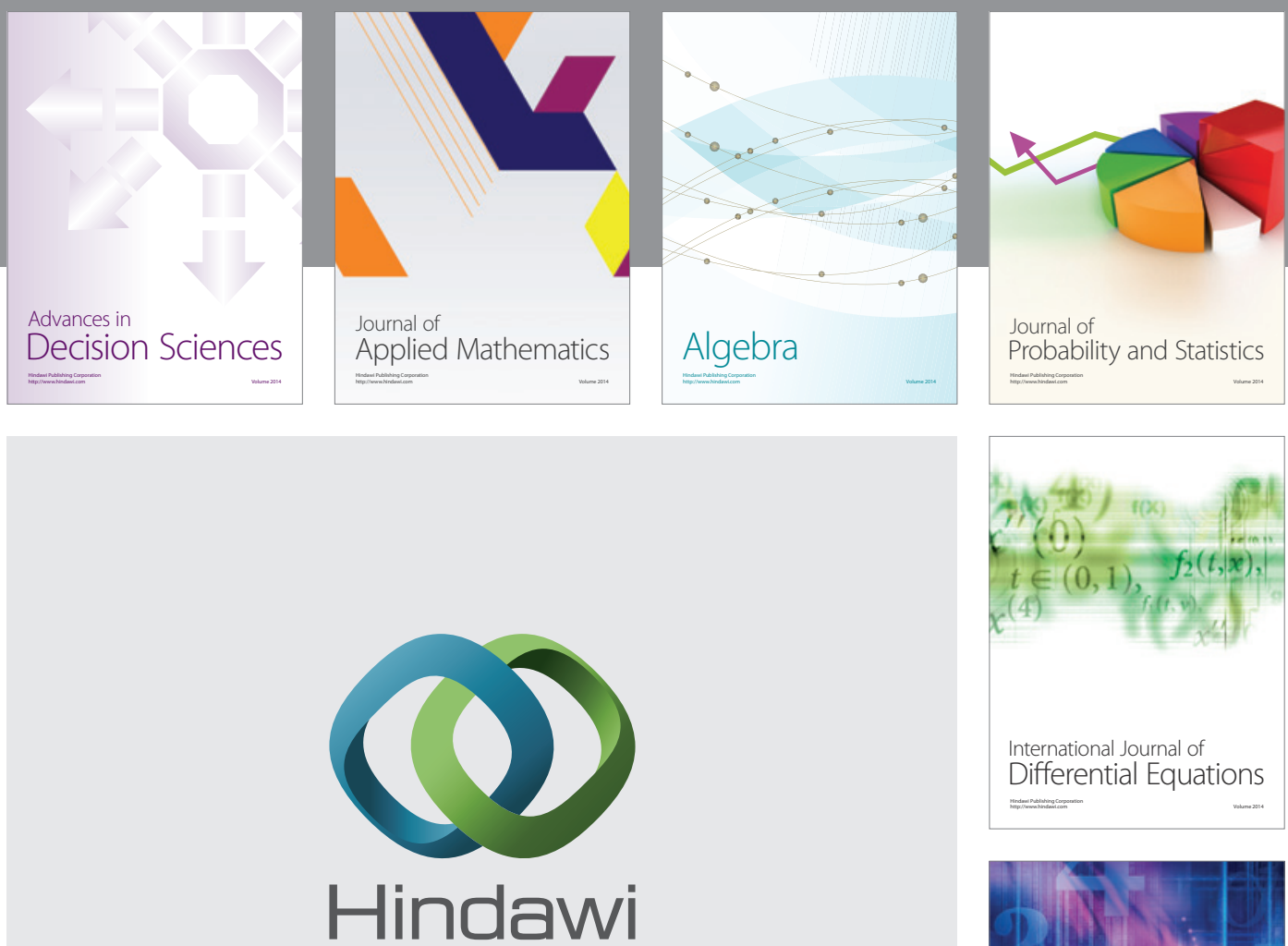

Submit your manuscripts at http://www.hindawi.com
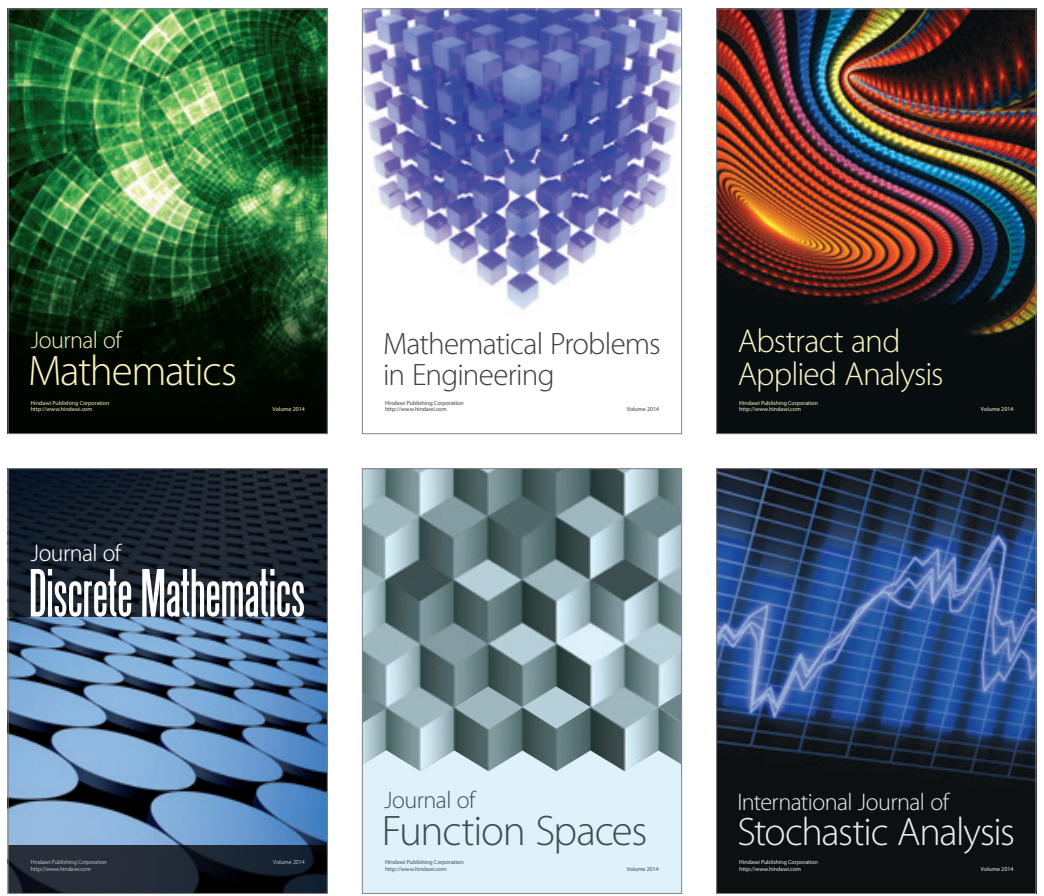

Journal of

Function Spaces

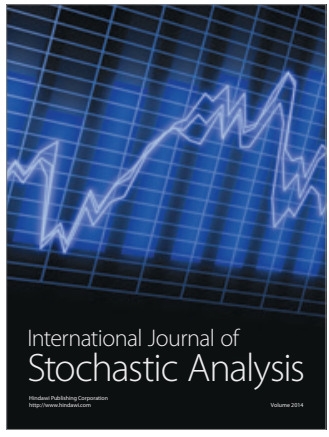

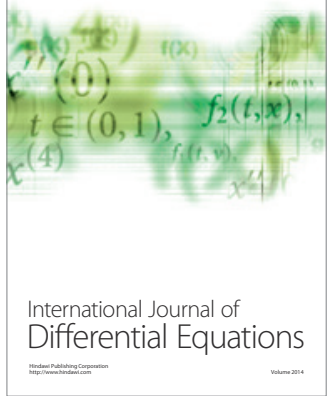
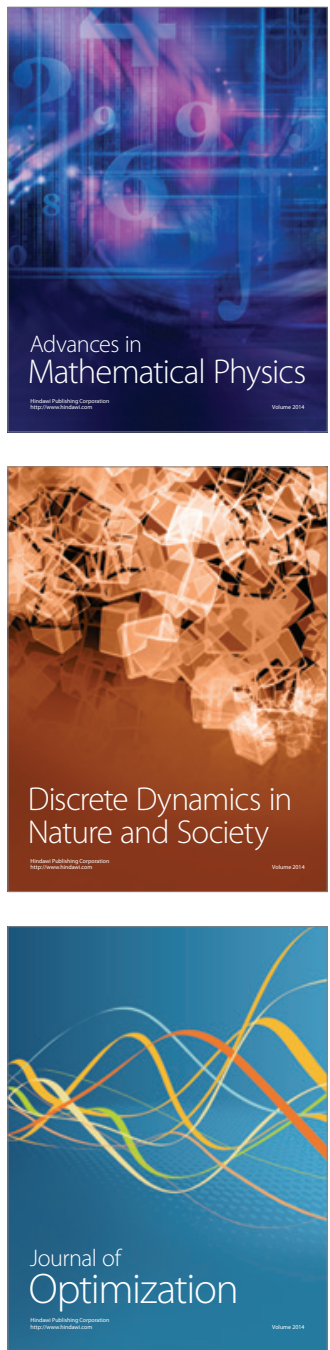